\title{
AS ORGANIZAÇÕES REGIONAIS E A PROMOÇÃO E PROTEÇÃO DA DEMOCRACIA: reflexões a partir das práticas de intervenção democrática na América do Sul
}

\author{
Andrea Ribeiro Hoffmann*
}

\begin{abstract}
O principal objetivo deste artigo é explorar se, e sob que condições, as organizações regionais podem contribuir para a promoção e proteção da democracia de seus estados-membros. Os principais fatores destacados são as identidades das organizações regionais, interesses dos países exercendo liderança, a pressão de atores externos, e os efeitos do fenômeno de sobreposição de regionalismos (overlapping regionalism), ou seja, os efeitos dos compromissos derivados da participação em diversas organizações simultaneamente, que podem ter mandatos semelhantes, complementares ou contraditórios. Em termos da análise empírica, este artigo analisa os compromissos com a democracia na América do Sul com foco na OEA, no Mercosul, e na Unasul. O caso da crise democrática no Paraguai de 2012 é usado para ilustrar as possibilidades e limites do papel das organizações regionais.

PAlAVRAS-Chave: Organizações regionais. Cláusula democrática. OEA. Unasul. Mercosul. Paraguai.
\end{abstract}

\section{INTRODUÇÃO}

A maioria das organizações regionais contemporâneas adotaram normas e criaram instrumentos para promover e proteger a democracia em seus estados-membros; até mesmo organizações onde participam estados que não são democracias plenas, tais como a Associação das Nações do Sudeste Asiático (Asean) ou o Conselho de Cooperação do Golfo (GCC). A literatura de regionalismo comparado tem buscado entender este fenômeno; um ponto de partida são as mudanças estruturais no nível global após o fim da Guerra Fria. Historicamente, a primeira organização regional que incluiu um comprometimento com a democracia foi a Organização dos Estados Americanos (OEA), criada em 1948, mas a grande parte das normas e instrumentos para promover e proteger a democracia foram estabelecidas a partir da década de 1990 (Börzel; Van Hüllen 2015).

A ideia de que organizações regionais

* Pontifícia Universidade Católica do Rio de Janeiro. Departamento de Relações Internacionais.

Rua: Marquês de São Vicente, 225. Vila dos Diretórios, Casa 2. Cep: 22451900. Gávea - Rio de Janeiro - Rio de Janeiro - Brasil. a_ribeiro_hoffmann@puc-rio.br podem ter um papel relevante no fortalecimento da democracia não é óbvia. A possibilidade de se promover a democracia de fora para dentro foi debatida na literatura sobre transições democráticas e democratização, mas não há um consenso sobre seus efeitos (O`Donell; Schmitter; Whitehead, 1986; Whitehead, 1996; Pevehouse, 2005). A proliferação das cláusulas de condicionalidade democrática nas organizações regionais pelo mundo é um tema extremamente relevante e que deve ser estudado em maior profundidade dado às incertezas sobre sua potencialidade, especialmente dada à inexistência de um regime consolidado nesta área no nível global, ou seja, no âmbito das Organizações das Nações Unidas ONU (Rich, 2001).

O principal objetivo deste artigo é explorar se, e sob que condições, as organizações regionais podem contribuir para a promoção e proteção da democracia de seus estados-membros. Os principais fatores destacados são as identidades das organizações regionais, interesses dos países exercendo liderança, a pressão de atores externos, e os efeitos do fenômeno de sobreposição de regionalismos (overlapping 
regionalism), ou seja, os efeitos dos compromissos derivados da participação em diversas organizações simultaneamente, que podem ter mandatos semelhantes, complementares ou contraditórios. Em termos da análise empírica, este artigo analisa os compromissos com a democracia na América do Sul com foco na OEA, no Mercado Comum do Sul (Mercosul) e na União das Nações Sul-Americanas (Unasul). O caso da crise democrática no Paraguai de 2012 é usado para ilustrar as possibilidades e limites do papel das organizações regionais.

A primeira parte do artigo discute os compromissos para promoção e proteção da democracia no nível global; a segunda parte, aborda brevemente os compromissos das organizações regionais; a terceira parte analisa os compromissos e práticas de promoção e proteção da democracia pela OEA, Mercosul e Unasul em mais detalhes; a quarta parte analisa a atuação dessas organizações durante crises democráticas em seus estados-membros, e a quinta, discute os fatores que levam os Estados e organizações regionais a intervirem em crises democráticas. O artigo conclui com uma análise dos desafios que as organizações regionais enfrentam para ter um papel efetivo na promoção e proteção da democracia de seus Estados-membros.

\section{NORMAS E INSTRUMENTOS GLO- BAIS PARA PROMOÇÃO E PROTE- ÇÃO DA DEMOCRACIA \\ ry o Pacto da Liga das Nações, não continha ne- a nhum compromisso explícito com a democra- ơ cia, exceto a referência a nós, os povos em seu Preâmbulo, dada a discordância sobre a per- tinência de incluir esse tema entre os estados signatários. Rich argumenta que, "o lugar ló- gico para que o conceito da democracia se de- senvolva como um princípio efetivo na ordem legal internacional é o regime de direitos hu- manos" (2001, p. 23). De fato, foi na Declara-}

ção Universal dos Direitos Humanos (Art. 21) onde, pela primeira vez, a "vontade popular" foi estabelecida como "base para a autoridade dos governos", e onde se explicita a recomendação de que a demanda por essa vontade fosse observada através de "eleições periódicas e gerais" (Art. 25). O Pacto Internacional dos Direitos Civis e Políticos definiu mecanismos processuais, mas foi assinado e ratificado por poucos países na época, pela mesma razão que não foram incluídos compromissos democráticos na Carta da ONU. A discordância sobre a priorização dos direitos civis e políticos, por um lado, e direitos sociais e econômicos, por outro, permaneceu como um dos principais obstáculos para a consolidação de um regime de promoção e proteção da democracia no plano global. Este foi o principal eixo de discórdia durante a Guerra Fria. Atualmente, cerca de 165 países já ratificaram este Pacto, mais de 85\% dos membros da ONU, mas ainda assim há uma discussão sobre especificidades culturais e preferências locais, inclusive entre os países ocidentais, gerando um debate intenso sobre prós e contras dos modelos de democracia representativa, participativa e deliberativa, assim como a persistência de diferenças entre as democracias liberais e democracias sociais (Pateman 1970, Fierlbeck 2008, Nardulli 2008).

Apesar de essas diferenças permanecerem, o final da Guerra Fria foi um divisor de águas nas atividades de promoção e proteção da democracia. A relação entre segurança, democracia e desenvolvimento foi reconceitualizada e, entre outros, políticas de desenvolvimento passaram a ser utilizadas como instrumentos para a promoção da democracia, criando oportunidades para o estabelecimento de sanções econômicas em casos de crises democráticas, tais como a suspensão da ajuda oficial ao desenvolvimento por parte dos doadores internacionais. Democracia, desenvolvimento e segurança também se tornaram mais interligados nas operações de paz e nas atividades de (re)construção de Estados.

No que se refere ao Direito Internacional, entre as normas que incluem referências 
à democracia, há o Programa de Ação adotado pela Conferência Mundial dos Direitos Humanos de Viena (1993), que estabelece que democracia, desenvolvimento e respeito pelos Direitos Humanos e liberdades fundamentais são interdependentes e se reforçam mutuamente (§ 8 da seção I); o Comentário Geral 25 do Comitê de Direitos Humanos da ONU (1996), que discorre sobre direitos de voto e direitos à igualdade no acesso à funções públicas; e as Resoluções 1999/57 sobre a Promoção do Direito à Democracia, e 2000/47 Promovendo e Consolidando a Democracia da Comissão de Direitos Humanos da ONU. A ONU também expandiu seu papel na área de democracia, além do regime de Direitos Humanos nas últimas décadas, especialmente na área de assistência eleitoral. Rich (op. cit., p. 26) também menciona a Conferência Internacional das Democracias Novas ou Restauradas, realizada pela primeira vez em 1988, e a Agenda para Democratização de 1996, promovida por Boutros-Boutros Ghali, como marco importante. Em 2007, a Assembleia Geral da ONU aprovou a Resolução 62/7 sobre o apoio da ONU aos esforços dos governos para promoção e consolidação das democracias novas ou restauradas, e declarou o dia 15 de setembro como Dia Internacional da Democracia. O conceito de Responsabilidade para Proteger estabeleceu condições sobre as quais a soberania dos estados-nacionais deveria ser condicionada ao tratamento dos indivíduos por parte dos governos nacionais. A ONU também criou uma série de instrumentos para promover a democracia e a governança democrática, tais como o Fundo da ONU para a Democracia (United Nations Democracy Funed Undeff. ${ }^{1} \mathrm{~A}$ democracia é agora referida no site da ONU como um dos valores centrais universais e indivisíveis da $O N U,{ }^{2}$ apesar de nem todos seus estados-membros serem democráticos.

\footnotetext{
${ }^{1}$ http://www.un.org/democracyfund/

2 http://www.un.org/en/globalissues/democracy/democracy_and_un.shtml
}

\section{ORGANIZAÇÕES REGIONAIS E CON- DICIONALIDADE DEMOCRÁTICA}

A maioria das organizações regionais adotou compromissos com a democracia nas últimas duas décadas; o Quadro 1 lista as principais normas e instrumentos criados, tais como declarações, protocolos, programas de ação, e órgãos especializados. Embora exista uma grande variação no grau de legalização e efetividade destas normas e instrumentos, pode-se observar uma tendência global de ampliação de sua abrangência e nível de detalhamento. A maioria das organizações estabeleceu mecanismos de assistência e observação eleitorais, e várias adotaram cláusulas democráticas, que estipulam mecanismos para lidar com crises tais como mediação, sanções políticas, econômicas, e no caso de organizações africanas, militares (Börzel; van Hüllen, 2015, p. 8-9).

\section{NORMAS E INSTRUMENTOS RE- GIONAIS PARA PROTEÇÃO E PRO- MOÇÃO DA DEMOCRACIA NA AME- RICA DO SUL}

\section{Organização dos Estados Americanos (OEA)}

A democracia é um dos principais princípios do Tratado constitutivo da OEA, a Carta de Bogotá (1948), mas somente nos anos 1990, no final da Guerra Fria, a organização consolidou um sistema de normas e mecanismos para proteger e promover a democracia (Herz, 2011). Em 1990, foi criada a Unidade para a Promoção da Democracia com o objetivo de prover assistência técnica e consultoria para os Estados-membros sobre atividades relacionadas ao fortalecimento de políticas e procedimentos democráticos, quando por eles solicitado. Em 1991, a Assembleia Geral adotou a Resolução 1080, um instrumento através do qual o Secretário Geral pode convocar o Conselho Permanente para examinar um caso de 
Quadro 1 - Compromissos com a democracia em Organizaçōes Regionais (seleçăo)

\begin{tabular}{|c|c|}
\hline Organização Regional & Documento \\
\hline União Africana (UA) & $\begin{array}{l}\text { - African Charter on Human and Peoples' Rights (1981) } \\
\text { - Protocol to the African Chapter on Human and Peoples' Rights on the } \\
\text { Establishment of an African Court on Human and Peoples' Rights (1998) } \\
\text { - Lomé Declaration on the framework for an OAU response to } \\
\text { unconstitutional changes of government (2000) } \\
\text { - Declaration on the Principles Governing Democratic Elections in Africa } \\
\text { (2002) } \\
\text { - African Charter on Democracy, Elections and Governance (2007) }\end{array}$ \\
\hline $\begin{array}{l}\text { Associação das Nações } \\
\text { do Sudeste Asiático } \\
\text { (Asean) }\end{array}$ & $\begin{array}{l}\text { - } \quad \text { Bali Concord (2003) } \\
\text { - } \quad \text { Vientiane Action Programme (2004) } \\
\text { - } \\
\text { - } \\
\text { - } \\
\text { - }\end{array}$ \\
\hline $\begin{array}{l}\text { Liga dos Estados } \\
\text { Árabes (LAS) }\end{array}$ & $\begin{array}{l}\text { - Pact of the League of Arab States (1945) } \\
\text { - Tunis Declaration (2004) }\end{array}$ \\
\hline $\begin{array}{l}\text { Fórum das Ilhas do } \\
\text { Pacifico (PIF) }\end{array}$ & $\begin{array}{l}\text { - Biketawa Declaration (2000) } \\
\text { - PIC Agreement (2000) } \\
\text { - Pacific Plan (2005) } \\
\text { - Political Governance and Security (Strategic Plan 2009-2011) }\end{array}$ \\
\hline $\begin{array}{l}\text { Associação Sul -Asiática } \\
\text { para a Cooperação } \\
\text { Regional (Saarc) }\end{array}$ & $\begin{array}{l}\text { - } \quad \text { SAARC Charter (1985) } \\
\text { - } \quad \text { SAARC Social Charter (2004) } \\
\text { - } \quad 16^{\text {th }} \text { Summit Declaration (2010) }\end{array}$ \\
\hline $\begin{array}{l}\text { Comunidade do } \\
\text { Sudeste Africano para o } \\
\text { Desenvolvimento } \\
\text { (SADC) }\end{array}$ & $\begin{array}{l}\text { - } \quad \text { SADC Charter, Art. } 5 \text { (1992) } \\
\text { - } \quad \text { Revised SADC Charter, Art. } 5.1 \text { (2001) } \\
\text { - Protocol on Politics, Defense and Security Co-operation, Art2 \&11 } \\
\text { (2001) } \\
\text { - Principles and Guidelines Governing Democratic Elections and a Code } \\
\text { of Conduct for Election Observers (2004) }\end{array}$ \\
\hline $\begin{array}{l}\text { Comunidade } \\
\text { Econômica dos estados } \\
\text { da África Ocidental } \\
\text { (ECOWAS) }\end{array}$ & $\begin{array}{l}\text { - Declaration of Political Principles (1991) } \\
\text { - } \quad \text { Revised Treaty (1993) } \\
\text { - Protocol relating to the Mechanism for Conflict Prevention (1999) } \\
\text { - } \\
\text { - ECotocol on Democracy and Good Governance (2001) } \\
\text { ECOS Conflict Prevention Framework (2008) }\end{array}$ \\
\hline \multicolumn{2}{|c|}{$\begin{array}{l}\text { Fontes: Börzel e Van Hüllen (2015); } \text { http://www.idea.int/democracydialog/upload/Annex A - Democracy-and Democracy Assistance (IDFA); } \\
\text { Related_Charters_and_Declarations_of_Regional_Organizations.pdf. (acesso em 27/04/2016) }\end{array}$} \\
\hline \multicolumn{2}{|c|}{$\begin{array}{l}\text { crise democrática, assim como encontros com do conceito de democracia e formas como ela } \\
\text { os Ministros de Relações Exteriores, ou ses- } \\
\text { sões especiais da Assembleia Geral, no prazo do a ação coletiva dos Estados (Herz, 2004; } \\
\text { de dez dias. Em 1992, foi assinado o Protocolo Oliveri, 2014). Em 2005, durante a } 35^{\text {a }} \text { sessão } \\
\text { de Washington, que entrou em vigor em 1997, da Assembleia Geral, foi discutida a possibili- } \\
\text { e estabeleceu poderes para suspender Estados- dade de ampliar os mecanismos de proteção } \\
\text { membros no caso de governos eleitos demo- da democracia, proposta feita pelos EUA, mas } \\
\text { craticamente serem removidos do poder pela a maioria dos estados latino-americanos se } \\
\text { força. Em 2001, foi concluída a Carta Intera- opôs, privilegiando os princípios da soberania } \\
\text { mericana Democrática, que definiu elementos e da não intervenção (Burges, 2005). }\end{array}$} \\
\hline
\end{tabular}




\section{Mercado Comum do Sul (Mercosul)}

\section{Protocolo de Ushuaia}

O Protocolo de Ushuaia, também referido como a cláusula democrática do Mercosul, foi assinado em julho de 1998 e entrou em vigor em janeiro de 2002. Seu Artigo 1 estabelece que a existência de instituições democráticas é uma condição essencial para o processo de integração regional. Os Artigos 2 e 3 estabelecem que em caso de ruptura da ordem democrática, o protocolo deve ser implementado. Os Art. 4 e 5 discorrem sobre os procedimentos e medidas a serem adotados nos casos de crise tais como a suspensão dos direitos da parte afetada de participar dos processos decisórios, e a suspensão dos direitos e deveres perante a organização regional.

\section{Protocolo de Montevidéu sobre Democra- cia (Ushuaia II)}

O Protocolo de Montevidéu foi concluído em 20/12/2011 (Dec. CMC 27/11), mas ainda não entrou em vigor. Ele reafirmou o conteúdo do Protocolo de Ushuaia, e incluiu, em seu Art.1, que ele deve ser implementado não somente em caso de ruptura democrática, mas também em caso de ameaça de ruptura e violação da ordem constitucional, ou qualquer outra situação que coloque em risco o exercício legitimo de poder e dos valores e princípios democráticos. Ushuaia II expandiu, assim, os casos nos quais a cláusula democrática do Mercosul pode ser implementada. O Art. 6 descreve, com maiores detalhes, as medidas que podem ser adotadas, incluindo fechamento de fronteiras (Art. 6), promoção da suspensão da parte afetada de outras organizações regionais e internacionais (Art. 6d) e outras sanções políticas e diplomáticas (Art. 6f). O Art. 7, no entanto, estabelece que as medidas não devem colocar em risco o bem-estar e os direitos humanos da população, e devem res- peitar a soberania e a integridade territorial da parte afetada.

\section{Protocolo de Direitos Humanos}

A democracia e, os Diretos Humanos têm sido tratados por instrumentos diferentes no Mercosul. A condicionalidade democrática foi tratada nos Protocolos de Ushuaia e Ushuaia II, como foi visto, enquanto que os direitos humanos foram tratados pelo Protocolo de Direitos Humanos, assinado em 2005 (em vigor em 2010). O Protocolo de Direitos Humanos estabelece que o respeito aos direitos humanos e às liberdades fundamentais constitui condição essencial para o processo de integração (Art.1). Ele prevê a suspensão da parte responsável por violações sérias e sistemáticas de direitos humanos e liberdades fundamentais, caso as consultas sejam improdutivas, especialmente em casos de crises institucionais ou estados de emergência previstos nas ordens constitucionais respectivas (Art. 3, 4).

\section{Outros instrumentos do Mercosul}

O Mercosul ainda conta com outros instrumentos para promover a democracia e os direitos humanos, tais como o Observatório da Democracia, criado em 2007, e que acompanha os processos eleitorais dos Estados-membros e coordena as atividades das missões de observação eleitoral. A Declaração Presidencial sobre Direitos Humanos de 2005 se referiu, pela primeira vez no Mercosul, ao direito à verdade e à luta contra a impunidade (Art. 5), estabelecendo que conhecer a verdade sobre eventos passados é um direito coletivo (Art. 6). O Protocolo Constitutivo do Parlamento do Mercosul também contém várias referências à democracia, aos direitos humanos e à boa governança dos Estados-parte. O Art. 4, que lida com suas competências, estabelece que ele deve elaborar e publicar relatórios anuais sobre a situação dos 
direitos humanos dos Estados-membros e que o Parlamento deve proteger a democracia dos Estados-membros, fazendo referência ao Protocolo de Ushuaia. A reunião de Altas Autoridades em Direitos Humanos do Mercosul, criada em 2004, e o Instituto de Políticas Públicas de Direitos Humanos, criado em 2009, também são instituições centrais no processo de consolidação da agenda de direitos humanos no Mercosul (Ventura; Rolim, 2002; Hoffmann, 2015). ${ }^{3}$

O sistema de solução de controvérsias do Mercosul não estabelece mecanismos específicos para litigação contra violações de direitos humanos, mas há uma discussão sobre a jurisdição do sistema atual (Lixinski, 2010; Giupponi, 2012). Alguns juristas argumentam que a expansão da jurisdição desse sistema não demanda, necessariamente, uma mudança em sua estrutura, mas a maioria dos especialistas considera difícil que isso ocorra na ausência de uma corte permanente e uma carta de direitos humanos (Sant'Anna Rosa, apud Lixinski, 2010, p. 357). Propostas nesse sentido foram discutidas, por exemplo, no contexto do Diálogo entre as Cortes Supremas dos Estadosmembros do Mercosul e do Fórum Permanente de Cortes Supremas do Mercosul, ambos criados em 2004. O estabelecimento de uma corte permanente regional, no entanto, exigiria mudanças consideradas de difícil aprovação nas Constituições do Brasil e do Uruguai.

O caso das papeleiras, levado ao Tribunal Arbitral Ad Hoc em junho de 2006 pelo Uruguai contra a Argentina, expôs os limites desta questão. Ele se refere ao bloqueio das pontes internacionais entre os dois países por grupos ambientalistas que protestavam contra $\dot{A}$ a construção de indústrias de celulose, paiิ peleiras, no Rio Uruguai. O caso é analisado $\therefore$ em detalhes por Lixinski (2010: 364), que argumenta que o laudo do Tribunal Arbitral Ad Hoc optou por uma interpretação restrita e deu

${ }^{3}$ A proteção dos Direitos Humanos também é tratada pela Decisão do Conselho Mercado Comum (CMC Dec.64/10), que aprovou o Plano de Ação para um Estatuto da Cidadania do Mercosul, a ser implementado até 2021, na ocasião do seu $30^{\circ}$ aniversário. preferência clara aos interesses econômicos e comerciais sobre a questão dos direitos humanos. O caso da suspensão do Paraguai do Mercosul, em 2012, trouxe novos elementos a essa discussão. O Paraguai foi suspenso em junho de 2012, após o processo de impeachment contra o Presidente Lugo, interpretado como um golpe de estado pelos outros Estados-membros do Mercosul, que aplicaram os procedimentos estabelecidos pelo Protocolo de Ushuaia. ${ }^{4}$ O Presidente interino Federico Franco, no entanto, questionou a legalidade das decisões tomadas pelos Presidentes, e seu governo levou o caso ao sistema de solução de controvérsias do Mercosul. O laudo do Tribunal Permanente de Revisão 01/2012 foi contra o Paraguai, mas, significativamente, incluiu a discussão sobre suas competências para julgar casos políticos. O Tribunal Permanente de Revisão explicitamente estabeleceu que nada impede que os juízes julguem esses casos, mas não aplicou os procedimentos estabelecidos para casos excepcionais previstos no Protocolo de Olivos, alegando que eles eram restritos a casos comerciais (Perotti, 2013). O Tribunal Permanente de Revisão não resolveu, portanto, a questão sobre se casos de violações da ordem democrática e direitos humanos referidos nos Protocolos de Ushuaia e de Direitos Humanos poderiam ser trazidos à corte em situações não emergenciais.

\section{União das Nações Sul-Americanas (Unasul)}

A Unasul foi criada em 2008, em um contexto de mudanças de paradigma de modelos de integração regional na América do Sul, onde o livre-comércio perdeu a centralidade para outras atividades de cooperação nas áreas de infraestrutura e políticas sociais. A estrutura institucional da Unasul reflete essa mudança, dispondo de Conselhos para tratar

${ }^{4}$ A suspensão foi anunciada durante a Cúpula do Mercosul, realizada em Mendonza no 'Comunicado Conjunto de los Presidentes de los Estados Partes del Mercosur, Mondonza, 29/06/2012'; e posteriormente aprovada no Conselho Mercado Comum em sua decisão CMC Dec.28/12, 30/07/2012. 
de temas como desenvolvimento social, saúde, educação e cultura, além do Conselho de Economia e Finanças. O Conselho de Desenvolvimento Social, por exemplo, tem um mandato amplo, e seus objetivos principais são contribuir para a consolidação de sociedades mais justas e promover mecanismos de cooperação para um desenvolvimento integral social e com redução de assimetrias (Tussie; Riggirozzi, 2014).

A Unasul também estabeleceu mecanismos para a promoção da cooperação nas áreas de segurança e defesa, como o Conselho de Defesa Sul-Americano (Briceno; Hoffmann, 2015). Um elemento central no conceito de segurança e defesa da Unasul é o compromisso coletivo com a proteção e a promoção da democracia e dos direitos humanos. A Unasul tem uma cláusula democrática, na forma de um protocolo assinado em novembro de 2010 e em vigor desde 2014 (Protocolo Adicional ao Tratado Constitutivo sobre o Compromisso com a Democracia). Tal Protocolo reforça o compromisso com a proteção e a promoção da ordem democrática, dos direitos humanos e liberdades fundamentais e do estado de direito. Todos esses aspectos são considerados como condições essenciais e indispensáveis para a participação na Unasul. O Art. $1^{\circ}$ estabelece que ele deve ser aplicado em casos de ruptura ou ameaça de ruptura da ordem democrática, de violações da ordem constitucional ou qualquer situação que prejudique o exercício legitimo do poder e a aplicação dos valores e princípios democráticos. O Art. 4 discorre sobre a suspensão da participação do estado violador nos órgãos da Unasul, assim como seus direitos e deveres sob o Tratado Constitutivo, e prevê o fechamento de fronteiras, comércio, comunicação, provisão de energia, serviços e outras sanções políticas e diplomáticas. Assim como no caso do Mercosul, o compromisso com a democracia e os direitos humanos é balanceado com os princípios da soberania e da não intervenção, não incluindo a possibilidade de sanções militares ou referências ao princípio da Responsabilidade de Proteger (RtP).

\section{A PRÁTICA DA PROTEÇÃO DA DE- MOCRACIA NA AMERICA DO SUL}

As organizações regionais sul-americanas têm reagido durante crises democráticas em seus Estados-membros, por meio de sanções políticas, incluindo declarações e até mesmo a suspensão dos estados violadores. Até o presente momento, não foram implementadas sanções econômicas, e, como foi visto acima, não há previsões para sanções militares. A atuação da OEA inclui a invocação da Resolução 1080 e da Carta Democrática, e casos de ação preventiva via atuação do Conselho Permanente. A reação do Mercosul fez referência a Declarações Presidenciais e ao Protocolo de Ushuaia; e a da Unasul, Declarações Presidenciais e o Protocolo Democrático.

A Resolução 1080 da OEA foi invocada nas seguintes crises: golpe contra o Presidente Jean-Bertrand Aristide, no Haiti (1991); autogolpe do Presidente Alberto Fujimori no Peru (1992); greves e instabilidade política na Venezuela (1992); tentativa de golpe na Guatemala (1993); e crises no Paraguai (1996, 1999, 2012). A Carta Democrática foi invocada na tentativa de golpe contra o Presidente Hugo Chávez na Venezuela (2002), na instabilidade do Equador (2005, 2010), na crise de governabilidade da Bolívia (2003, 2005, 2008), no Peru (2004) e na Nicarágua $(2004,2005)$, além do golpe contra o Presidente Manuel Zelaya em Honduras (2009) (Feldmann, 2015, p. 2).

O Mercosul reagiu prontamente nas crises de 1996, 1999 e 2012 no Paraguai, e no processo de adesão da Venezuela. O Protocolo de Ushuaia só foi formalmente implementado na crise do Paraguai de 2012. Os casos das crises de 1996 e 1999, no Paraguai, foram extensivamente analisados na literatura (Valenzuela, 1996, 1999; Stömberg, 1997; Ribeiro Hoffmann, 2007). Apesar de o Protocolo de Ushuaia não existir em 1996 e não estar em vigor em 1999, o Mercosul fez referência à condicionalidade democrática em ambos os 
casos, principalmente via Declarações Presidenciais (3/1996 e 2/1999). Como já foi mencionado acima, a crise de 2012 foi bem mais complexa, mas, afinal, o Protocolo de Ushuaia foi formalmente implementado e a participação do Paraguai nos órgãos do Mercosul foi suspensa até as novas eleições, realizada em agosto de 2013. O Mercosul também reagiu durante crises nos seus estados associados em geral através de notas para imprensa, tais como nos casos da Bolívia em 2003 (renúncia do Presidente Gonzalo Lozada), em 2005 (renúncia do Presidente Carlos Mesa) e em 2008 (Referendo Revogatório); o Peru em 2005 (tentativa de golpe contra o Presidente Toledo); e o Equador em 2005 (destituição do Presidente Lucio Gutierrez). Uma Comunicação Presidencial foi feita no caso da Bolívia em 2008, apoiando a Declaração de La Moneda da Unasul, a favor do Presidente Evo Morales (Comunicado de CMC_2008_ACTA02, parágrafo 13). O Mercosul também enviou observações eleitorais ao Referendo Revogatório de 2008. A Venezuela foi objeto de controvérsia e a ratificação do tratado de adesão foi adiada pela oposição, nos congressos do Brasil e do Paraguai, que questionaram as qualidades democráticas do governo do então Presidente Hugo Chávez (Santiso, 2003; Pinheiro, 2009). ${ }^{5}$ O governo brasileiro evitou um engajamento direto no debate sobre a definição da democracia ou a avaliação do ๑ regime do governo de Chávez, permanecendo . em um entremeio entre querer promover a democracia, e respeitar o princípio da soberania ‡. e da não intervenção (Santiso, 2003), mas o శึ então Ministro de Relações Exteriores, Celso 돌 Amorim, afirmou que "viver em coexistência \& com democracias no Mercosul vai ajudar o foro talecimento da democracia na Venezuela" (Jornal Estado de São Paulo, 21/11/2007).

No caso da Unasul, sua primeira reação

${ }^{5}$ O Tratado de Adesão da Venezuela foi assinado em 4 de julho de 2006, ratificado pela Argentina em 14 de fevereiro de 2007 e Uruguai em 30 de agosto de 2007. A ratificação no Brasil foi no dia 4 de março de 2010. O Paraguai não ratificou, mas os outros estados-membros aproveitaram o período de suspensão para aprovar a entrada da Venezuela em julho de 2012 (Decisão 27/12, 30/07/2012). foi no caso da crise democrática da Bolívia de 2008, quando foi emitida a Declaração de La Moneda em apoio ao Presidente Evo Morales, como mencionado acima. A Unasul também reagiu na crise política do Paraguai em 2012, quando a clausula democrática foi invocada, e o Paraguai foi suspenso até as eleições de agosto de 2013.

\section{ANALISANDO A DECISÃO DE IN- TERVIR PARA PROTEGER A OR- DEM DEMOCRÁTICA}

A literatura de intervenções discute os fatores que levam organizações a intervirem em seus estados membros em casos de crises democráticas. ${ }^{6}$ Van der Vleuten e Ribeiro Hoffmann (2010) destacam a relevância das identidades das organizações regionais (definida com base na existência e tipo de instrumentos para proteção democrática, e o nível e estabilidade dos regimes domésticos dos estadosmembros), interesses materiais e ideacionais dos países exercendo liderança regional, e da pressão de atores externos em um estudo comparativo incluindo seis casos em três organizações regionais (UE, Mercosul e SADC).

Um fator adicional, que se tornou mais evidente recentemente complexifica o contexto das intervenções democráticas: a existência de mais de uma organização com mandato para proteção democrática. A questão dos chamados 'mandatos sobrepostos' ainda foi pouco analisada na literatura, e não há consenso sobre suas causas e impacto (Weiffen et al, 2013; Nolte, 2014). Nos casos do Paraguai em 1996 e 1999 a sobreposição de mandatos com o compromisso democrático não causou problemas, pois tanto a OEA como o Mercosul definiram o processo como uma crise democrática e atu-

${ }^{6}$ Intervenção é definida como a interferência planejada em assuntos domésticos com o objetivo de defender a democracia; esse conceito se alinha ao de Joseph Nye (2005), para quem intervenções incluem manifestações que variam desde condenações verbais, sanções econômicas até intervenções militares, diferentemente da definição mais tradicional nos estudos de segurança, onde ela é identificada com intervenções militares. 
aram de forma complementar. No caso da crise no Paraguai de 2012, no entanto, a situação foi mais complexa do que uma tentativa de golpe de estado tradicional; os Estados-membros da OEA, da Unasul, e do Mercosul tiveram interpretações divergentes sobre e legitimidade e legalidade do processo de impeachment contra o Presidente Lugo e a reação do Congresso Paraguaio, levando a reações diversas entre a OEA por um lado, e Unasul e Mercosul por outro lado. Os partidos e população paraguaia foram desta forma apoiados e criticados por diferentes atores externos, o que levou a um aumento da politização e instabilidade política no curto prazo.

O caso do Paraguai de 2012 ilustra como a prática da proteção e promoção da ordem democrática por organizações regionais é mais complexa do que até então analisado, e como a questão da definição da democracia e modelos democráticos, bem como os efeitos do fenômeno do regionalismo e mandatos sobrepostos, precisam ser incorporados na análise para uma compreensão mais sofisticada do papel das organizações regionais e a ordem democrática dos seus Estados-membros.

Nas Américas, além da OEA, Unasul e Mercosul, a Comunidade Andina, Comunidade do Caribe (Caricom), Mercado Comum da América Central e a Comunidade de Estados Latino-Americanos e Caribenhos (CELAC) estabeleceram normas e instrumentos para promover e proteger a democracia, causando divergências na interpretação do que constitui uma ruptura democrática ou um risco de ruptura democrática em casos como o Paraguai e Venezuela, e também Honduras.

\section{CONSIDERAÇÕES FINAIS}

Este artigo explorou a forma como a democracia tem sido tratada no âmbito da cooperação multilateral, tanto universal, no Sistema das Nações Unidas, como nas organizações regionais, no caso da América do Sul.
Foi visto que os compromissos com a ordem democrática aumentaram em número e qualidade desde o final da Guerra Fria, sobretudo no âmbito regional. As organizações regionais têm intervido em seus Estados-membros em nome da democracia, dependendo da configuração de identidades e interesses regionais, e da configuração de organizações com mandatos sobrepostos.

No caso da América do Sul, o principal desafio que as organizações regionais encontram para proteger e promover a democracia na região encontra-se na questão da definição de democracia, que se torna mais complexo dado o fenômeno de regionalismos sobrepostos. Apesar da referência às normas regionais, a decisão de classificar um evento como uma crise é um processo predominantemente político. A relação entre direito e política foi evidenciada, sobretudo, no processo de impeachment no Paraguai. No caso da América do Sul, o debate sobre modelos de democracia se aprofundou nos últimos anos, e vários países têm promovido experiências inovadoras, a partir de discussões sobre democracia representativa, participativa e deliberativa, o que torna a análise do que é legal ou legítimo ainda mais complexa (Vitale, 2006; Pogrebinschi, 2013). Algumas experiências são menos controversas tais como referendos e as opções de participação direta como o orçamento participativo. Outros casos, tais como a Bolívia e a Venezuela, no entanto, o fato da democracia participativa não ser vista apenas como um mecanismo político, mas como parte de um projeto que inclui também um modelo econômico alternativo, o chamado Socialismo do Século XXI, contribuíram para o aumento da polêmica acerca da definição de democracia, e a polarização entre grupos e países dentro e fora da região.

Se, por um lado, há uma urgência em se aprofundar a discussão sobre modelos de democracia e a legitimidade política em contextos culturais diversos, não se pode correr o risco de banalizar o próprio conceito da democracia; este é um desafio central para orga- 
nizações regionais e seu papel na proteção e promoção da democracia.

Recebido para publicação em 26 de outubro de 2015 Aceito em 21 de novembro de 2015

\section{REFERÊNCIAS}

ARRIGHI, J. M. OEA - Organização dos Estados Americanos. São Paulo: Manole, 2004.

BÖRZEL, T.; HÜLLEN, V. (Ed.) Governance transfer by regional organizations. Palgrave Macmillan, 2015.

BRICENO-RUIZ, J.; HOFFMANN, A. R. Post-hegemonic regionalism, UNASUR and the reconfigutration of cooperation in South America. Canadian Journal of Latin American and Caribbean Studies, forthcoming, 2015.

BURGES, S. W. 'The OAS as democratic policeman?'. Focal Point [Online], 4, 2005. Available at: <http://www.focal. ca/pdf/focalpoint_june2005.pdf $>$.

CASTANEDA, J. Latin Americas left turn. Foreign Affairs, v. 85, n. 3. 2006.

FIERLBECK, K. Globalizing democracy. Power, legitimacy and the interpretation of democratic ideas. Manchester \& New York: Manchester University Press, 2008.

FINNEMORE, M. The purpose of intervention: changing beliefs about the use of force. (Ithaca: Cornell University Press), 2003.

GIUPPONI, B. O. International Law and sources of law. In: MERCOSUR: an analysis of a 20-year relationship. Leiden Journal of International Law, 25, p. 707-737, 2012.

HELD, D. Models of democracy. Cambridge \& Malden: Polity Press, 2006.

HERZ, M. The Organization of American States. Routledge, 2011.

HOFFMANN, A. R. Political Conditionality and Democratic Clauses in the EU and Mercosur. In: HOFFMANN, A. R.; VLEUTEN, A. V. D. (Ed.) Closing or widening the gap? Legitimacy and democracy in Regional Integration $\stackrel{0}{0}$ Organizations. Aldershot: Ashgate, p.173-89? 2007.

At last: protection and promotion of human rights by Mercosur. In: Governance transfer by regional 命 organizations, edited by BÖRZEL, T.; HÜLLEN, V. V. Palgrave Macmillan, 2015.

$\therefore$ LIXINSKI, L. Human Rights in Mercosur. In: FILHO, M. \% T. F.; LIXINSKI, L.; GUIPONNI, M. B. O. (Ed.) The law of o Mercosur. Hart Publishing, 2010.

के MERKE, F. Política exterior de Argentina e eleição a institutional: a OEA no espelho da UNASUR e do Mercosul. Lua Nova, n. 90, 2013.

MORALES, M. La doble estatalidad abierta: interamericanización y mercosurización de las

ô. Constituciones suramericanas. Estudos Avançados de

Tireitos Humanos. Democracia e Integracão Jurídica:

$\geq$ Emergência de um novo direito público. Rio de Janeiro: ڤ Elsevier, 2013.

NOLTE, D. Latin America's New Regional Architecture: a Cooperative or Segmented Regional Governance Comple? RSCAS 2014/89 Robert Schuman Centre for Advanced Studies, 2014.
NYE, J. S. Understanding International Conflicts. An Introduction to Theory and History, 5th ed. New York: Pearson/Longman, 2005.

O 'DONELL, G.; SCHMITTER, P.; WHITEHEAD, L. (Ed.) Transitions from autoritatian rule. JHU Press, 1986.

PATEMAN, C. Participation and democratic theory. Cambridge University Press, 1970.

PEROTTI, A. La justifícacion jurídica del ingresso de Venzuela al Mercosur es totalmente nula. 2013.: <http:// www.abogados.com.ar/la-justificacion-juridica-delingreso-de-venezuela-al-mercosur-es-totalmentenula/10986>.

PEVEHOUSE, J. C. Democracy from Above. Regional Organizations and Democratization. Cambridge: Cambridge University Press, 2005.

PINHEIRO, F. Incorporação da Venezuela ao Mercosul: razões para o impasse no Legislativo brasileiro. OPSA/ IUPERJ. Observador On-line v. 4, n. 3, 2009.

RICH, R. Bringing Democracy into International Law. Journal of Democracy. v. 12, n. 3, 2001.

SACASA, M. H. Soberanía Clásica, un Princípio Desafiado... ¿Hasta Dónde? Managua: Mauricio Herdocia Sacasa. 2005.

SANTISO, C. The Gordian knot of Brazilian foreign policy: promoting democracy while respecting democracy' Cambridge Review of International Affairs, v. 16, n. 2, p. 343-58, 2003.

SMILDE, D. Participation, politics and culture. Emerging fragments of Venezuela's Bolivarian democracy. In: Venezuela's Bolivarian Democracy: participation, politics, and culture under Chávez, edited by SMILDE, D.; DUKE, D. H. University Press Books, 2011.

STRÖMBERG, T. Did regional integration save democracy in Paraguay? Working Paper for the Bertil Ohlin Institutet, Oslo. 1997. Available at: <www.ohlininstitutet.nu/ skrifter/paraguay.doc>

VALENZUELA, A. Paraguay: the Coup that didn't Happen. Journal of Democracy, v. 8, n. 1, p. 43-55, 1997.

The collective defense of democracy. Lessons from the Paraguayan crisis of 1996'. 1999. Available at: <http:// www.wilsoncenter.org/subsites/ccpdc/pubs/valenz/valefr. $\mathrm{htm}>$

VENTURA, D.; ROLIM, M. Os Direitos Humanos e o Mercosul: uma agenda (urgente) para além do Mercado'. 2002. Available at: < http://www.rolim.com.br/2002/_pdfs/ dhMercosul.pdf- $>$.

VITALE, D. Between deliberative and participatory democracy. Philosophy and Social Criticism, n. 32, 2006.

VLEUTEN, Van der; HOFFMANN, Ribeiro. Explaining the enforcement of democracy by regional organizations: comparing EU, mercosur and SACD. Journal of Common Market studies, v. 48, n. 3, p. 737-758, 2010.

WEIFFEN, B.; NOLTE, D.; WEHNER. L. Overlapping security institutions in South America: The case of OAS and Unasur. International Area Studies, v. 16, n. 4, p. 370389, 2013.

WHITEHEAD, L. (Ed.) The international dimensions of democratization. Europa and the America. Oxford University Press, 1996. 


\section{REGIONAL ORGANIZATIONS AND THE PROMOTIONAL AND PROTECTION OF DEMOCRACY: thoughts on the practices of democratic intervention in South America}

\author{
Andrea Ribeiro Hoffmann
}

The main goal of this article is to explore if, and under which conditions, regional organizations can contribute for the promotion and protection of the democracy in their state-members. The main highlighted factos are the identities of the regional organizations, the interests of the leading countries, the pressure of external actors, and the effects of the overlapping regionalism phenomenon, that is, the effects of the commitments derived from the participation of several organization simultaneously, which can have similar, complementary or contradictory precepts. In terms of empirical analysis, this article analyzes the commitments with democracy in South America, focusing on the OAS, the MERCOSUL and the Unasul. The case of the 2012 Peruvian democracy crisis is used to ilustrate the possibilities and limitations $\mathrm{f}$ the part of regional organizations.

KeYwORDS: Regional organizations. Democratic clause. OAS. Unasul. Mercosul. Paraguay.

\section{LES ORGANISATIONS RÉGIONALES ET LA PROMOTION ET LA PROTECTION DE LA} DÉMOCRATIE: réflexions basées sur les pratiques d'intervention démocratique en Amérique du Sud

\author{
Andrea Ribeiro Hoffmann
}

L'objectif principal de cet article est d'examiner si, et dans quelles conditions, les organisations régionales peuvent contribuer à la promotion et à la protection de la démocratie dans ses états membres. Les principaux facteurs mis en évidence sont l'identité des organisations régionales, les intérêts des pays leaders, la pression des acteurs extérieurs et les effets du phénomène de superposition des régionalismes (overlapping regionalism), c'est-à-dire les effets des engagements découlant de la participation de diverses organisations en même temps qui peuvent mener des actions similaires, complémentaires ou contradictoires. En termes d'analyse empirique, cet article analyse les engagements envers la démocratie en Amérique du Sud, surtout en ce qui concerne l'OEA dans le MERCOSUR et l'UNASUR. Le cas de la crise démocratique au Paraguay en 2012 sert à illustrer les possibilités et les limites du rôle des organisations régionales.

Mot-CLÉs: Organisations régionales. Clause démocratique. OEA. Unasur. Mercosur. Paraguay. 
